\title{
PROFISSÕES: Tantas e quais escolher?
}

Recebido em 25.12.2012. Aprovado em 28.12.2012 Avaliado pelo sistema double blind review

\section{Elza Aparecida da Cruz}

cruzguedes@hotmail.com

Escola Estadual José Ribeiro Guimarães - Mogi das Cruzes- RJ - Brasil.

\section{Resumo}

Diante da constatação da falta de interesse dos jovens pelos estudos, da falta de sentido da vida provocada pela falta de oportunidades sociais e culturais e pela falta de visão do mundo do trabalho e dos projetos universitários promovidos pelos governos, é que a equipe escolar resolveu pesquisar e elaborar um Plano de Empreendimento. Tendo como base a Lei de Diretrizes e Bases da Educação (LDB, 1996) que deseja uma escola democrática e participativa, autônoma e responsável, flexível e comprometida, atualizada e inovadora, humana e holística. Tais princípios contidos nos seus artigos vão encontrar concordância com esse Plano de Empreendimento acerca das profissões que a escola pretende desenvolver.

A equipe escolar sentiu necessidade da execução deste empreendimento, sendo assim, o valor solicitado ao edital será de $R \$ 39.531,47$, destinados à compra de alguns equipamentos, instalação dos mesmos e pintura em salas de aula; fretamento de ônibus; como também despesas corrente, material de consumo e manutenção dos euipamentos.

É um Plano que possibilitará a ampliação do repertório dos alunos sobre o mundo do trabalho, novas perspectivas de futuro e consequentemente a transformação do seu meio, resultando, assim, em ganho inigualável para a sociedade como um todo. $\mathrm{E}$, consequentemente, a melhora dos resultados das avaliações externas da escola.

É um empreendimento que tem como pano de fundo o Programa de Melhoria da Aprendizagem nas escolas, da Fundação Novo Brasil - Educação para o futuro e que a equipe conta com o apoio financeiro a fim de que se possa executar o Plano de Empreendimento que será apresentado detalhadamente nos próximos capítulos.

Palavras-chaves: Educação. Plano profissional. Plano de Empreendimento.Profissões. 


\section{Contexto da escola}

A Escola Estadual "José Ribeiro Guimarães " era um espaço antigo de madeira o qual foi demolido e substituído por um prédio de alvenaria há 06 anos, passou, atualmente, por nova ampliação e reforma. Conta com 10 salas de aula, sala de professores, sala de secretaria, sala de informática, sala de leitura, sala da Direção, sala de Coordenação Pedagógica, um elevador, despensa, refeitório aberto, cozinha, 11 sanitários para alunos, 04 para administração e professores, 01 depósito, 01 almoxarifado, amplo pátio coberto, espaços de acessibilidade, amplo jardim externo ao prédio, quadra poli-esportiva coberta, áreas livres e estacionamento de veículos.
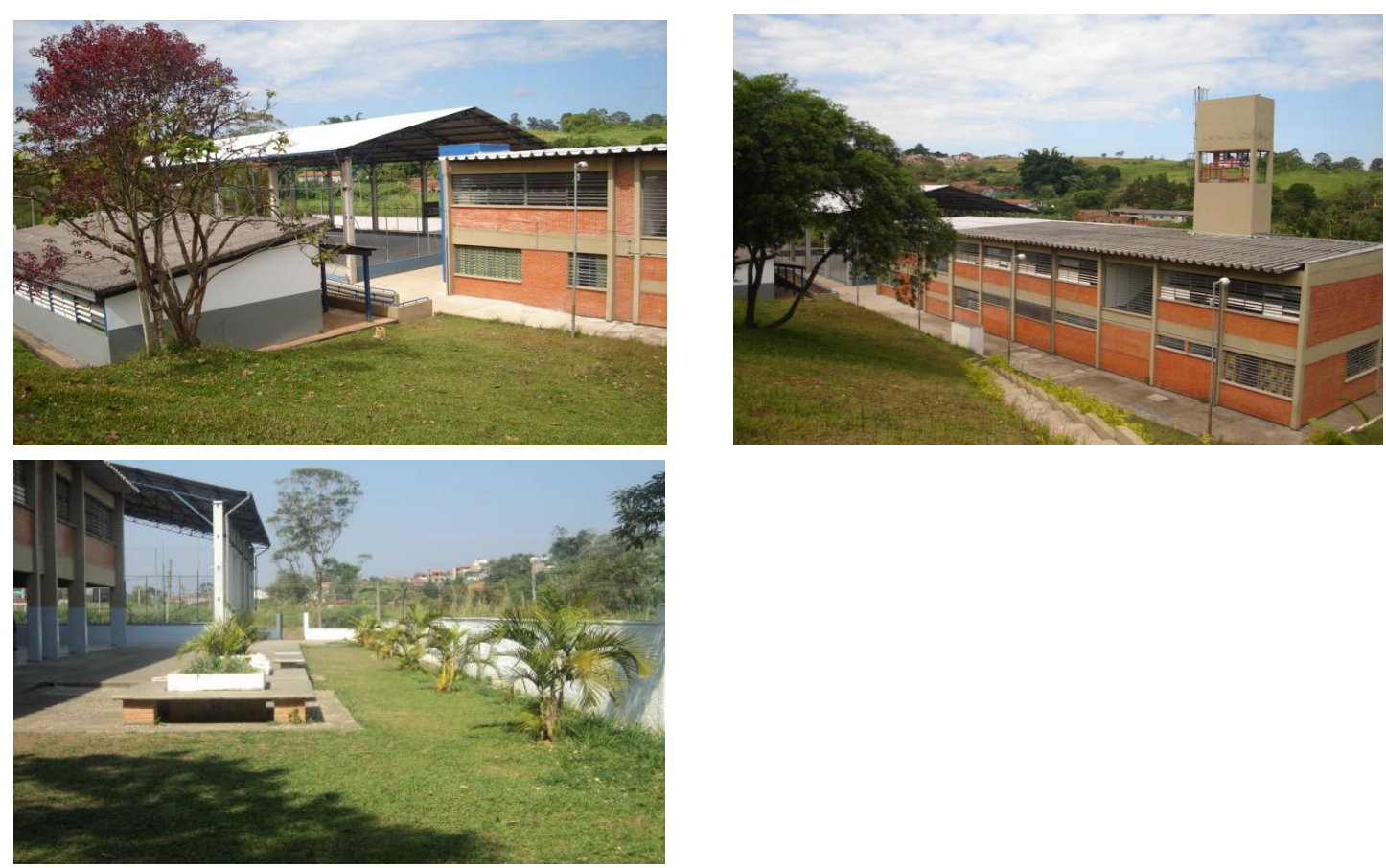

Figura 1: Fotos da Escola Estadual José Ribeiro Guimarães

Missão: Nossa missão é oferecer um ensino de qualidade, garantindo a participação ativa da comunidade escolar, contribuindo para a formação integral dos alunos, para que eles possam agir construtivamente na transformação do seu meio.

Visão: Ser referência no processo de desenvolvimento de competências através da adoção de metodologia diversificada, eficiente e eficaz e da otimização na utilização dos recursos tecnológicos.

\section{Valores:}

EXCELÊNCIA: buscamos incessantemente a qualidade em tudo o que fazemos em nossa escola.

ÉTICA: trabalhamos em elevado senso de compromisso, seriedade e respeito em todas as nossas ações.

INOVAÇÃO: incentivamos a busca de soluções criativas e inovadoras na solução dos desafios.

RESPEITO: às diferenças individuais, dificuldades de aprendizagem e a complexidade do humano. 
A demanda é atendida com vinte turmas, organizadas em dois turnos manhã e tarde, sendo:

\begin{tabular}{|c|c|c|}
\hline \multicolumn{2}{|c|}{$N^{\circ}$ DE TURMAS } & ANO ESCOLAR \\
\hline \multirow{4}{*}{$\begin{array}{l}\text { Ensino Fundamental } \\
\text { (Transição para o } \\
\text { ensino de } 9 \text { anos) }\end{array}$} & $6^{\circ}$ ano & 3 classes com 101 alunos \\
\hline & $6^{a}$ série & 3 classes com 90 alunos \\
\hline & $7^{\mathrm{a}}$ série & 3 classes com 94 alunos \\
\hline & $8^{\mathrm{a}}$ série & 3 classes com 102 alunos \\
\hline \multirow{3}{*}{ Ensino Médio } & $1^{\text {a }}$ série & 4 classes com 105 alunos \\
\hline & $2^{\mathrm{a}}$ série & 2 classes com 62 alunos \\
\hline & $3^{\mathrm{a}}$ série & 2 classes com 64 alunos \\
\hline \multicolumn{2}{|c|}{ Total de alunos atendidos } & 618 \\
\hline
\end{tabular}

Há onze alunos portadores de necessidades especiais que dependendo da necessidade são atendidos por professores especialistas. Há acessibilidade em toda infraestrutura escolar.

\section{Equipe escolar}

\begin{tabular}{|c|c|}
\hline \multicolumn{2}{|c|}{ PESSOAL ADMINISTRATIVO } \\
\hline Diretor & 01 \\
\hline Vice-diretor & 01 \\
\hline Gerente & 01 \\
\hline Agente de organização & 06 \\
\hline Agente de serviços & 02 \\
\hline Terceirizados - limpeza & 02 \\
\hline TOTAL & 13 \\
\hline \multicolumn{2}{|c|}{ DOCÉNCIA } \\
\hline Professoras Coordenadoras & 02 \\
\hline Mediadora de conflitos & 01 \\
\hline Interlocutoras & 02 \\
\hline Cuidadora & 01 \\
\hline Auxiliares (recuperação) & 02 \\
\hline Responsável sala de leitura & 01 \\
\hline DISCIPLINAS DO CURRÍCULO & QUANTIDADE \\
\hline Língua Portuguesa & 05 \\
\hline Língua Inglesa & 02 \\
\hline Arte & 03 \\
\hline Educação Física & 03 \\
\hline História & 03 \\
\hline
\end{tabular}


Elza Aparecida da Cruz

\begin{tabular}{|c|c|}
\hline Geografia & 03 \\
\hline Filosofia & 01 \\
\hline Sociologia & 01 \\
\hline Matemática & 05 \\
\hline Ciências & 02 \\
\hline Física & 02 \\
\hline Biologia & 02 \\
\hline Química & 01 \\
\hline Eventuais & 05 \\
\hline TOTAL & $\mathbf{4 7}$ \\
\hline
\end{tabular}




\section{PROFISSÕES: Tantas e quais escolher?}

\section{Características mais marcantes do local onde a escola se insere}

A Escola Estadual "José Ribeiro Guimarães " situa-se num bairro afastado, mas pertencente à cidade de Mogi das Cruzes e que ainda possui características rurais com chácaras e sítios explorados pelo cultivo do cogumelo. Em virtude da boa localização ambiental, da existência de mananciais e clima favorável a recuperação da boa saúde, o espaço é preservado por Lei Ambiental. Assim sendo, a instalação de indústria é autorizada com restrições, dificultando o interesse do poder público e privado em investimentos locais tanto de infraestrutura, cultural, esportivo como de lazer aos moradores, os quais vêm aumentando paulatinamente e modificando, assim, a estrutura ambiental.

A Unidade Escolar foi criada no ano de 1991, em virtude da luta dos moradores pelo espaço educacional, pois à época havia apenas uma escola pública e esta situada na ponta extrema do bairro, dificultando 0 acesso dos pequenos. Assim, foi construída em madeirite para atendimento rápido da reivindicação. No entanto, o "barracão", como era chamado, perpetuou por treze anos e, somente, em 2004, a comunidade local ganhou um prédio de alvenaria. Simultaneamente a nova instalação, a escola que atendia apenas ao ciclo I, do Ensino fundamental, passou a oferecer, também, o ciclo II, gerando grandes transformações e a construção de novas instituições escolares, assegurando todo um trabalho coletivo de participação e democratização educacional. A partir de 2012, com a municipalização, veio nova reorganização e a escola passou a atender o Ensino Médio e continuou com os alunos das séries finais do Ensino Fundamental.

Parte da população é carente e trabalhadora, geralmente migrada de outros Estados do Brasil (Nordeste principalmente) que reside em habitações ilegais com um mínimo de conforto, geralmente inacabadas e de alvenaria. A Prefeitura oferece água encanada em boa parte das casas, assim como a eletricidade e 0 calçamento. Metade do bairro, incluindo a escola, não usufrui esgoto público.

Não contando com empresas, uma grande parte da população local vê-se obrigada a grandes deslocamentos diários, em busca de trabalho em outros bairros da cidade e Grande São Paulo, despendendo de muitas horas e grande sacrifício.

Uma parte dos terrenos e imóveis do local, ainda, é de invasão, ou seja, foram cercados ou construídos de maneira irregular ou ilegal. Não há bancos próximos, apenas pequenos comércios, feito de algumas padarias, botequins, quitandas, lojinhas e pequenos mercados, dentro do perfil de poder aquisitivo da população local.

A falta de áreas de recreação e lazer adequados para os jovens aprofunda ainda mais a vulnerabilidade social do bairro, pois, aliada à falta de oportunidades de emprego, canaliza as energias da juventude para a violência.

A Escola mantém um bom relacionamento com a comunidade e estimula a participação da maioria nas atividades regulares da instituição e nas ações proporcionadas pela própria comunidade do entorno em parceria com a Unidade Escolar aos finais de semana e épocas especificas de comerações. 


\section{Identificação do problema ou da oportunidade}

\begin{tabular}{|c|c|c|}
\hline \multicolumn{2}{|c|}{ SITUAÇÃO GERAL DA ESCOLA NO IDEB } \\
\hline IDEB Brasil & Ciclo I & Ciclo II \\
\hline IDEB do município & 4,7 & 3,9 \\
\hline IDEB da escola em 2009 & 5,5 & 4,3 \\
\hline IDEB da Escola em 2011 & 5,0 & 4,4 \\
\hline & 5,6 & 5,1 \\
\hline
\end{tabular}

\begin{tabular}{|c|c|c|}
\hline \multicolumn{2}{|c|}{ SITUAÇÃO DA ESCOLA NO IDESP } & \\
\hline SARESP da escola em 2012 & Ensino Médio & 1,54 \\
\hline
\end{tabular}

A Escola Estadual José Ribeiro Guimarães enfrenta o seguinte problema: falta de interesse dos jovens, recém chegados para o Ensino Médio, sobre os programas oferecidos pelos governos Estadual e Federal, tanto os cursos de nível técnico como os superiores. Além do Baixo IDESP em 2012 apresentado pelos alunos do Ensino Médio que haviam chegado à escola.

A equipe escolar se reuniu e utilizou-se da ferramenta brainstorming para buscar soluções, ou seja, um caminho que possibilite aos alunos a ampliação do conhecimento sobre 0 mundo do trabalho e 0 desenvolvimento das competências leitora e escritora.

Num processo então de investigação, os docentes iniciaram uma pesquisa junto aos alunos e detectaram que quase $40 \%$ dos mesmos gostariam de discutir e conhecer profissões atuais. Muitos desconhecem os programas dos governos e nem sabem o que significa o ENEM, sua finalidade. Enfim, desconhecem 0 VENCE (técnico profissionalizante, programa estadual), o PROUNI e os demais programas.

Através da busca da raiz do problema, o grupo delineou o seguinte diagnóstico:

Segundo o SEADE, o bairro comporta muitas famílias mantidas apenas pelas mães que sozinhas cuidam em média de 4 a 6 filhos. Trabalham longe de casa, pois não há oportunidades de emprego no bairro, ficando as crianças e jovens sozinhos, na rua, provocando a vunerabilidade social;

os pais apresentam baixa escolaridade, ocasionando falta de estímulo ao processo de escolarização dos filhos;

não há oportunidades de lazer, esportes, cultura e de conhecimento sobre as profissões existentes no mescado, restando-lhes a reprodução das atividades profissionais dos pais (empregadas domésticas, pedreiros...);

os jovens não se inscrevem nos programas por falta de visão, de conhecimento sobre o mundo do trabalho;

a falta de oportunidade cultural dificulta o desenvolvimento da competência leitora e escritora para 


\section{PROFISSÕES: Tantas e quais escolher?}

pesquisa e da autonomia pessoal e profissional.

Durante as reuniões pedagógicas, o grupo vislumbrou um caminho em que a pesquisa junto aos alunos fizesse parte de um projeto sobre profissões, a fim de iniciá-los num mundo real e possível de transformação social. Os integrantes da equipe escolar iniciaram um processo de:

> contatos com as Universidades locais e escolas profissionalizantes para agendamento de visitações (excursões);

> parcerias com as Universidades com palestras com foco no mundo do trabalho;

> elaboração de situações didáticas de pesquisas sobre profissões existentes no mercado de trabalho, em sites e programas de entrevistas sobre o trabalho;

$>$ apreciação de filmes e vídeos que focam as escolhas profissionais e a profissionalização;

> discussões coletivas, mesas redondas sobre o mercado de trabalho;

$>$ leitura de livros que focam o mundo do trabalho;

$>$ ao final do ano a execução de uma feira sobre profissões na escola aberta à comunidade.

0 processo será acompanhado através dos seguintes indicadores: avaliações internas e externas (IDEB, IDESP) e do aumento de inscrições pelos alunos nos programas dos governos Estadual e Federal, tais como: ENEM, FIES, PROUNI, VENCE... e da participação em cursos técnicos profissionalizante, SENAl e do ingresso em cursos superiores através dos programas citados.

\section{Caracterização do produto/serviço \\ PROJETO \\ PROFISSÕES: Tantas e quais escolher?}

O corpo docente junto ao grupo de gestores da E. E. José Ribeiro Guimarães entende que o ensino deve ser centrado no aluno, tendo o professor como mediador, e isso implica deixar os alunos falarem e exporem as suas vontades e desejos acerca do que querem aprender, implica também usar estratégias nas quais possam discutir, negociar significados entre si e, nesse processo, o aluno deve ser ativo e não passivo. Com base nesse princípio, foi feita uma pesquisa com os alunos dessa Unidade de Ensino sobre qual tema eles gostariam de pesquisar e discutir ao longo do ano letivo de 2014.

\section{0 tema escolhido pelos alunos com $37 \%$ foi Profissões.}

Sabendo que a função do Ensino Médio é aprimorar os estudos adquiridos ao longo da vida escolar e inserir o aluno no mercado de trabalho, é que se propõem a realização do Projeto: Profissões "Tantas e quais escolher?" Assim, é de suma importância discutir o tema "profissões" e as ferramentas para identificar oportunidades de emprego e de trabalho, as características e as demandas mercadológicas.

\section{Objetivos}


Todos os professores da escola devem incentivar os alunos, principalmente os do Ensino Médio, a respeito do vestibular e suas diversas possibilidades, sendo a escolha da profissão um dos principais fatores, já que envolve a questão de onde estudar o curso desejado.

Deve ser abordado as formar de ingresso nas universidades públicas como USP, UNICAMP, UNESP, entre outras, bem como a importância na participação de provas como o ENEM que permitem o ingresso em instituições públicas como UFABC e UNIFESP não só de São Paulo, como em todas as Universidades Federais do País. Além disso, o próprio ENEM proporciona o PROUNI que facilita 0 ingresso em universidades, dando bolsas de até $100 \%$ em todo o país.

Os alunos devem conhecer até mesmo as Universidades de sua cidade. Em Mogi das Cruzes temos três universidades particulares e uma pública. As duas maiores universidades da cidade, a UBC e UMC, oferecem algumas vantagens que vão além do PROUNI, como o PRA VALER (UBC) e o MAIS ESTUDO (UMC). Estes projetos propiciam o financiamento do curso elou ajuda de custo com redução de valor nas parcelas dos cursos. Fora este projeto, o governo federal oferece a opção de Financiamento Universitário, o FIES.

É interessante mostrar aos alunos as diversas opções para ingressar numa universidade. Realmente, com todo o suporte que se tem hoje, só não faz universidade quem realmente não quer. Por isso, é papel do professor incentivar os alunos a se inscreverem no ENEM e a prestarem os vestibulares. Para isso, devem fazer uso em suas aulas, de questões de vestibulares como forma de prepararem os alunos, na medida em que considerarem relevante.

\section{Objetivos específicos}

Este projeto tem por objetivo apresentar aos alunos a diversidade de profissões e esclarecer a importância dos estudos para a inserção no mercado de trabalho, além de propiciar espaço para discussão e debate sobre a importância de cada uma delas. O projeto tem como foco os seguintes objetivos:

Ampliar o conhecimento sobre as diferentes profissões existentes;

$>$ Saber quais as profissões que dominam o mercado de trabalho;

$>$ Refletir sobre as diferentes profissões;

$>$ Pesquisar a faixa salarial de cada profissão;

$>$ Saber escolher a profissão do futuro - almejada;

$>$ Analisar os benefícios e as dificuldades de cada profissão;

> Analisar e refletir sobre as exigências necessárias para a formação de algumas profissões;

> Analisar a demanda de trabalho no mercado;

$>$ Conceituar o empreendedorismo (proativos; trabalho formal e informal);

$>$ Produzir apresentação com o uso dos multimeios. 


\section{PROFISSÕES: Tantas e quais escolher?}

\section{Levar os alunos a se questionarem sobre:}

- Qual a minha escolha profissional? Tenho o perfil adequado à minha escolha?

- Quais as opções de cursos universitários que tenho? Qual a sua duração?

- Que atribuições essa profissão exige? (atividades relativas à profissão).

- Como está o mercado de trabalho nessa área?

- Quais os tipos de atividades que deverei desempenhar?

- Quais os campos de atuação e as especializações para essa profissão?

\section{Público Alvo:}

Alunos do Ensino Fundamental (ciclo II) ao Ensino Médio.

\section{Recursos / materiais:}
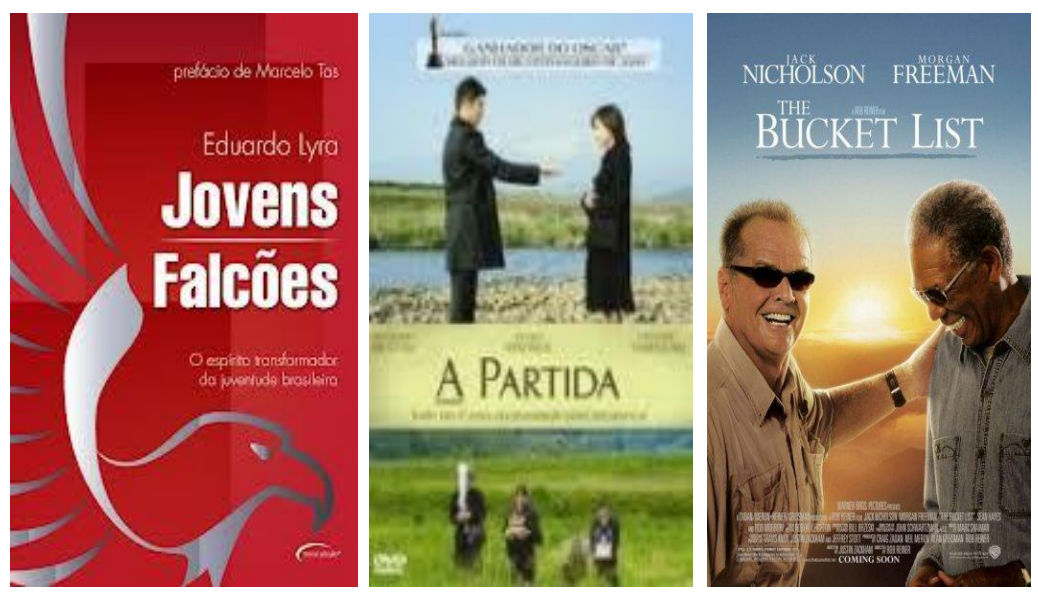

Palestras com vários profissionais, vídeos (ver links abaixo), visitações a universidades, feiras, o livro "Jovens Falcões", revistas, jornais impresso e virtual, telejornais com uso efetivo das TICs, os filmes 'A Partida' e o 'The Bucket List' sites http://guiadoestudante.abril.com.br/

\section{Critério De Organização De Trabalho}

Cada professor abordará e desenvolverá o tema com sua turma de coordenação e em seguida algumas atividades serão desenvolvidas com os professores especialistas.

CRONOGRAMA Inicial - passo a passo:

Atividade a ser desenvolvida com o professor coordenado de sala :

\begin{tabular}{|c|l|}
\hline Datas & \multicolumn{1}{c|}{ Atividades } \\
\hline Até 08/04/2014 & Entrega da lista de profissões escolhidas pelos alunos. \\
\hline Até 15/04/2014 & $\begin{array}{l}\text { - Organização dos grupos } \\
\text { - Pesquisa sobre os diferentes tipos de profissão } \\
\text { - Elaborar enquetes com os alunos. }\end{array}$ \\
\hline
\end{tabular}




\section{Elza Aparecida da Cruz}

\begin{tabular}{|l|l|}
\hline ATPC & - Apresentação da pesquisa e discussão com os professores. \\
$22 / 04 / 2014$ &
\end{tabular}

\section{Vídeos}

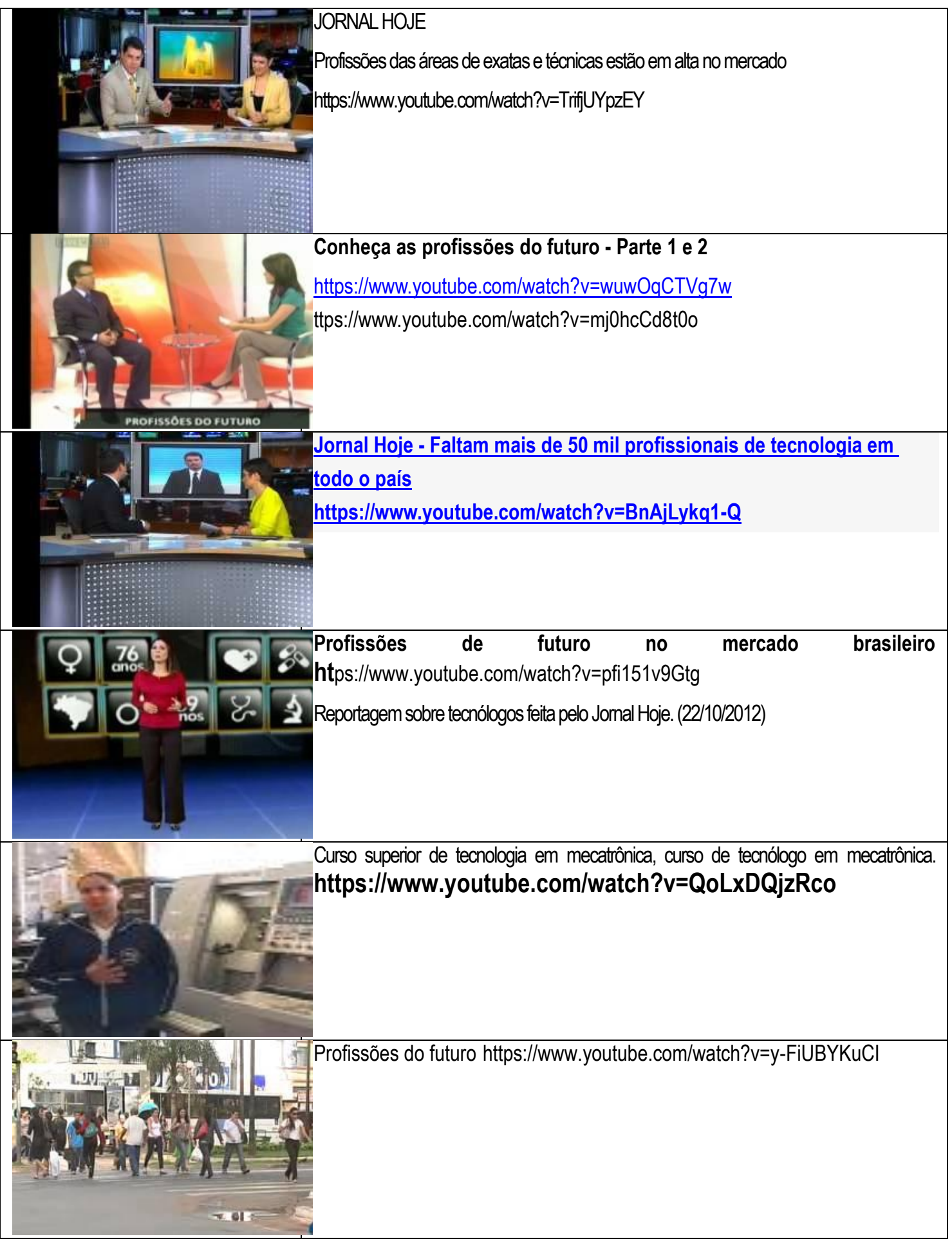




\section{PROFISSÕES: Tantas e quais escolher?}

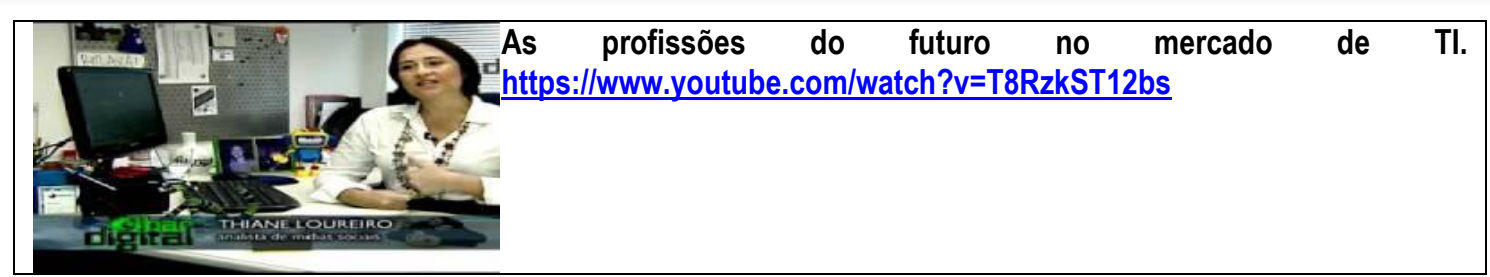

\section{Cronogramas de atividades (Palestras e Excursões e Visitas)}

\begin{tabular}{|c|c|}
\hline \multicolumn{2}{|r|}{ Parceria com a Universidade Braz Cubas } \\
\hline 23 a $27 / 04$ & Palestras com os profissionais de Direitos, de Farmácia e de Assistência Social. \\
\hline \multicolumn{2}{|r|}{ Parceria com a Universidade de Mogi das Cruzes } \\
\hline 06 a $11 / 04$ & Palestras com profissionais de Psicologia e Web Designer \\
\hline$\overline{X X / 05 / 2014}$ & $17^{\mathrm{a}}$ Feira do Estudante EXPO CIEE 2014 \\
\hline \multirow[t]{3}{*}{20 a $26 / 05$} & \multirow[b]{2}{*}{ CEnTro Paula Souza } \\
\hline & \\
\hline & Visitas à Fatec \\
\hline
\end{tabular}

Ajudar o aluno a estudar o mercado de trabalho, saber onde procurar por oportunidades, a saber se apresentar numa entrevista e elaborar um currículo.

- Mostrar aos alunos onde eles podem buscar oportunidades de emprego, como em sites de busca de empregos ou casas de emprego na sua cidade:

- INFOJOBS - www.infojobs.com.br

- CURRICULUM -www.curriculum.com.br

○ Catho - www.catho.com.br

○ CIEE - www.ciee.org.br - IMPORTANTE!

- NUBE - www.nube.com.br

- Mostrar que existem várias opções de estágios e trabalhos para jovens aprendizes em programas do governo.

- Trabalhar com os alunos o livro Jovens Falcões e explorar o gênero relato de experiências e levar os alunos a refletir e discutirem sobre os relatos, pesquisar sobre a biografia do autor do livro.

FEIRA DAS PROFISSÕES - semana de 23 de setembro especificamente os dias 26 e 27 -09-2014. Semana na qual os alunos irão apresentar suas pesquisas e a escola estará aberta para a comunidade 
para que estes apreciem as atividades desenvolvidas pelos alunos (Cartazes com gráficos, apresentações em power point, palestras entre outros.)

\section{Estratégia de implementação \\ MATRIZ SWOT/FOFA DA ESCOLA ESTADUAL JOSÉ RIBEIRO GUIMARÃES}

\begin{tabular}{|c|c|}
\hline FORÇAS & FRAQUEZAS \\
\hline $\begin{array}{l}\text { Infraestrutura; } \\
\text { Materiais pedagógicos e tecnológicos; } \\
\text { Docentes comprometidos e que fazem uso de metodologias de ensino } \\
\text { diferenciadas; } \\
\text { Sala de leitura em uso constante; } \\
\text { Projeto interdisciplinar sobre as profissões; } \\
\text { Planejamento coletivo do plano de empreendimento com busca do } \\
\text { aprimoramento constante das ações desencadeadas pelo grupo; } \\
\text { Uma parcela significativa dos pais é presente, participativa, } \\
\text { colaborando na formação acadêmica dos filhos; } \\
\text { O Projeto vai de encontro aos interesses de uma parte dos alunos: } \\
\text { PREFERÊNCIA DOS ALUNOS } \\
\text { PARA TEMAS DE } 2013 \\
\text { Fonte: Pesquisa realizada na EE. José Ribeiro Guimarães em } 2013 . \\
\text { Elaboração Própria. }\end{array}$ & $\begin{array}{l}\text { Uma parte dos alunos ainda não domina com proficiência } \\
\text { a leitura e a escrita; } \\
\text { Muitos alunos desconhecem as inúmeras profissões } \\
\text { existentes no mercado de trabalho; } \\
\text { A maioria dos alunos desconhece as oportunidades de } \\
\text { programas oferecidos pelos governos estadual e federal } \\
\text { sobre cursos técnicos e superiores, por isso a falta de } \\
\text { interesse pelo mundo do trabalho. }\end{array}$ \\
\hline $\begin{array}{l}\text { OPORTUNIDADES } \\
\end{array}$ & AMEAÇAS \\
\hline 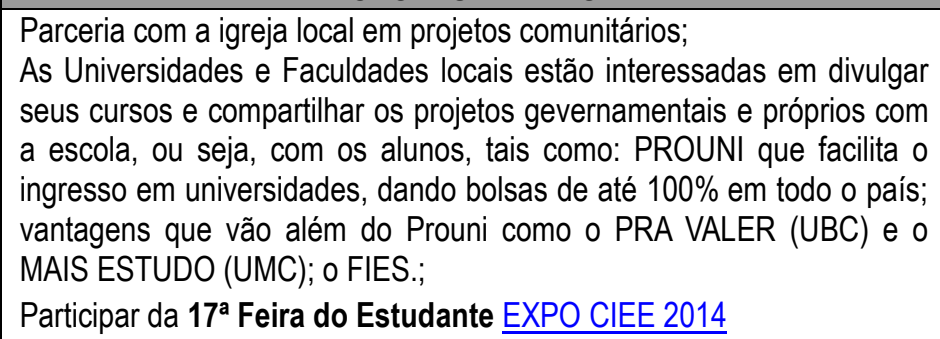 & $\begin{array}{l}\text { Carência financeira: os alunos mais velhos precisam } \\
\text { trabalhar mais cedo para ajudar no sustento da casa; } \\
\text { As Políticas Públicas do Governo na mudança de } \\
\text { atendimento da demanda pela escola; } \\
\text { Falta de emprego no bairro em virtude da Lei dos } \\
\text { mananciais, dificultando a instalação de empresas; } \\
\text { Forte reprodução das profissões exercidas pelos pais. }\end{array}$ \\
\hline
\end{tabular}




\section{Objetivos estratégicos}

\begin{tabular}{|c|c|c|}
\hline \multicolumn{3}{|c|}{ DEFINIÇÃO DAS ESTRATÉGIAS } \\
\hline OBJETIVOS & METAS & ESTRATÉGIAS \\
\hline $\begin{array}{l}\text { Melhorar a aprendizagem } \\
\text { dos alunos através da } \\
\text { ampliação do repertório } \\
\text { sobre o mundo do trabalho. }\end{array}$ & $\begin{array}{l}\text { Aumentar o IDESP da escola de } 1,54 \text { para } \\
5,00 \text { até o fim do projeto em } 2016 \text {. }\end{array}$ & $\begin{array}{l}\text { Mobilizar os docentes para: troca de } \\
\text { experiências; incentivo ao uso das TICs; } \\
\text { pesquisa junto aos alunos; planejamento } \\
\text { estratégico, execução e avaliação coletiva; } \\
\text { Mobilizar gestores para: acompanhamento e } \\
\text { controle das ações. }\end{array}$ \\
\hline $\begin{array}{l}\text { Aumentar a procura dos } \\
\text { alunos por cursos Técnicos e } \\
\text { Superiores oferecidos pelos } \\
\text { Governos Estadual } \\
\text { Federal. }\end{array}$ & $\begin{array}{l}\text { Aumentar em } 20 \% \text { ano após ano o número de } \\
\text { alunos interessados em cursar os técnicos do } \\
\text { RETEC e do VENCE; } \\
\text { Aumentar em } 20 \% \text { ano após ano o número dos } \\
\text { alunos inscritos no ENEM; } \\
\text { Aumentar em } 20 \% \text { ano após ano a procura dos } \\
\text { alunos em cursar as Universidades utilizando- } \\
\text { se dos programas oportunizados pelos } \\
\text { Governos Estadual e Federal. }\end{array}$ & $\begin{array}{l}\text { Projeto profissões: Tantas e quais escolher? } \\
\text { Movimento interdisciplinar. } \\
\text { Diagnóstico, ampliação do conhecimento dos } \\
\text { alunos sobre } 0 \text { mundo do trabalho, } \\
\text { consequentemente das profissões existentes, } \\
\text { através de pesquisas, enquetes, estudo de caso, } \\
\text { pesquisa de campo, estatísticas, gráficos, } \\
\text { participação em feiras, visita às universidades, } \\
\text { depoimentos, relatos, filmes, sites, elaboração } \\
\text { power point pelos alunos, exposições dos } \\
\text { alunos... }\end{array}$ \\
\hline 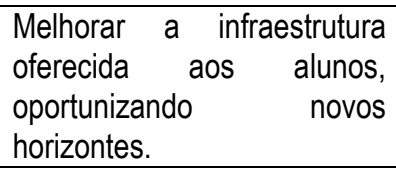 & $\begin{array}{l}\text { Oportunizar espaços mais agradáveis } \\
\text { estimulando-os a pesquisa e autonomia. }\end{array}$ & $\begin{array}{l}\text { Desenvolver estratégias de ensino diferenciadas } \\
\text { para estimular o interesse dos alunos pela busca } \\
\text { de um futuro transformador. }\end{array}$ \\
\hline
\end{tabular}

\begin{tabular}{|c|c|}
\hline INDICADORES & RESULTADOS \\
\hline $\begin{array}{l}\text { ID }=\frac{n^{0} \text { de alunos inscritos nos cursos técnicos }}{N^{0} \text { total de alunos das } 2^{\mathrm{a}} \text { ou } 3^{\mathrm{a}} \text { séries do EM }} \times 100 \\
\text { ID }=\frac{\mathrm{n}^{0} \text { de alunos inscritos no ENEM }}{\mathrm{N}^{0} \text { total de alunos das } 2^{\mathrm{a}} \text { ou } 3^{\mathrm{a}} \text { séries do EM }} \times 100\end{array}$ & $\begin{array}{l}\text { Aumento do número de alunos } \\
\text { concluintes do Ensino Médio } \\
\text { cursando universidades ou } \\
\text { faculdades através de } \\
\text { programas dos governos. }\end{array}$ \\
\hline$I D=\frac{n^{0} \text { de alunos inscritos nos Programas }}{N^{0} \text { total de alunos concluintes do EM }} \times 100$ & \\
\hline
\end{tabular}

\begin{tabular}{|l|l|l|}
\hline \multicolumn{1}{|c|}{ RECURSOS NECESSÁRIOS } \\
\hline \multicolumn{1}{|c|}{ O que vou precisar } & \multicolumn{1}{|c|}{ Descrição } & \multicolumn{1}{c|}{ Como obter } \\
\hline $\begin{array}{l}\text { Compra de equipamentos tecnológicos, } \\
\text { instalações e pequenos reparos na sala } \\
\text { de leitura e em cinco salas de aula. }\end{array}$ & $\begin{array}{l}\text { Aquisição de cinco datashows com } \\
\text { instalação dos mesmos em cinco salas } \\
\text { de aula e um home theater. Pintura em 05 } \\
\text { salas de aula e na sala de leitura. }\end{array}$ & $\begin{array}{l}\text { Recursos obtidos via Edital, PDE, PDDE, } \\
\text { FDE e Projetos da SEE. }\end{array}$ \\
\cline { 1 - 2 } Fretamento de ônibus e laches & $\begin{array}{l}\text { Fretamento de ônibus para os alunos, a } \\
\text { fim de visitarem as Universidades e } \\
\text { faculdades públicas e privadas locais, } \\
\text { além das empresas. }\end{array}$ & \\
\hline
\end{tabular}

\section{Marketing e comunicação}




\section{Elza Aparecida da Cruz}

O processo de comunicação do Projeto Profissões: tantas e quais escolher?, que será executado a partir de 2014, iniciar-se-á com um marketing integrado, primeiramente através da divulgação pelos gestores em reunião coletiva com os funcionários administrativos e corpo docente, ainda em 2013, a fim de que todos se comprometam de forma eficaz e eficiente com o novo serviço/produto ofertado pela instituição escolar. No decorrer, outras reuniões serão realizadas com os pais e alunos para apresentação do projeto que partiu da demanda de necessidades de aprendizagens e da falta de conhecimentos específicos sobre o mundo do trabalho entre os usuários da escola, sendo assim, essa oferta possibilitará boa aceitação pelos clientes (internos e externos), pois o foco é a superação profissional dos futuros cidadãos da região, o que beneficiará tanto a organização escolar como todos os seus clientes e usuários.

\section{Modelo de negócios}

Abaixo está a representação do modelo de negócios do projeto sobre profissões. O objetivo da escola é deixar claro sua forma de organização para gerar valor.

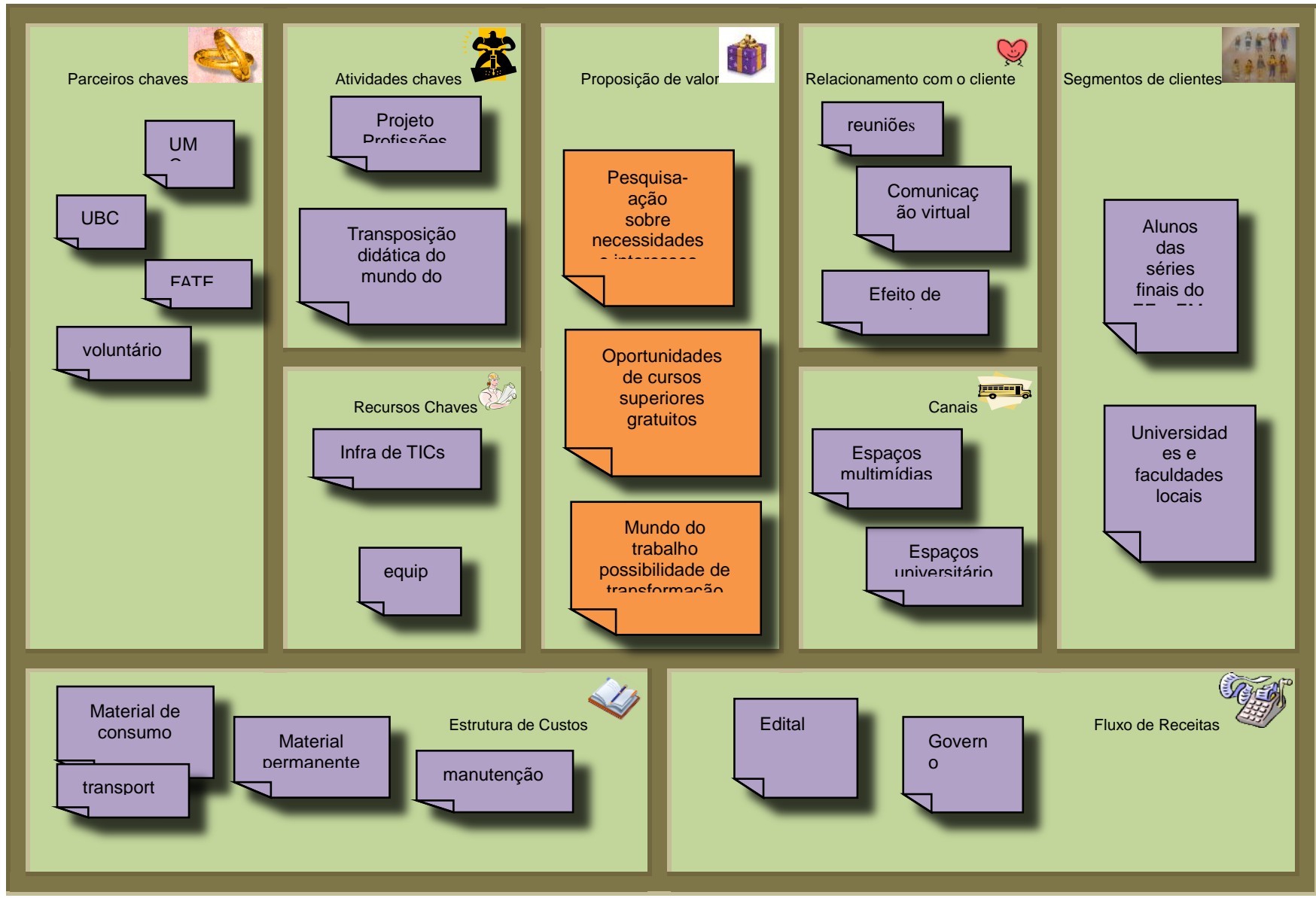

Organização e gerência do empreendimento

\section{Equipe gestora}




\section{PROFISSÕES: Tantas e quais escolher?}

O empreendimento será organizado e gerenciado pela equipe gestora, a qual se encontra preparada para acompanhar e controlar toda a execução do projeto pela equipe escolar, como mostra a tabela abaixo:

\begin{tabular}{|c|c|c|c|}
\hline Nome & Função & Formação/experiência & $\begin{array}{l}\text { Principais atividades } \\
\text { (no Projeto) }\end{array}$ \\
\hline Elza & Diretora & $\begin{array}{lcr}\text { MBA Gestão } & \text { Empreendedora } & \mathrm{em} \\
\text { educação. } & \text { Especialização } & \mathrm{em} \\
\text { alfabetização. Pedagogia. Artes. } 11 \text { anos } \\
\text { na direção, sendo } 9 \text { anos nesta escola, } 06 \\
\text { anos na vice-direção. } 17 \text { anos de } \\
\text { magistério. }\end{array}$ & $\begin{array}{l}\text { Gestora responsável pela tomada de preços, orçamentos } \\
\text { e prestação de contas das verbas destinadas à escola. } \\
\text { Acompanhar e controlar através de reuniões sistemáticas } \\
\text { com a equipe gestora todo o processo de planejamento, } \\
\text { execução, avaliação e análise das planilhas de controle } \\
\text { de observação das ações do projeto para possiveis } \\
\text { realinhamento, como também, através dos indicadores. }\end{array}$ \\
\hline Adriana & $\begin{array}{l}\text { Vice- } \\
\text { diretora }\end{array}$ & $\begin{array}{l}\text { Especialização em alfabetização. } \\
\text { Pedagogia. Magistério. } 22 \text { anos de } \\
\text { magistério, sendo } 15 \text { anos nesta escola e } 8 \\
\text { anos na função de vice-diretora. Em virtude } \\
\text { da experiência profissional acumulada se } \\
\text { envolve tanto com as questões } \\
\text { administrativas quanto pedagógicas de } \\
\text { forma eficiente e eficaz. }\end{array}$ & $\begin{array}{l}\text { Elaborar cronograma das ações do Projeto com seus } \\
\text { respectivos responsáveis e afixar no painel da sala dos } \\
\text { professores para divulgação e acompanhamento da } \\
\text { equipe. Comunicar através de reuniões os pais e alunos } \\
\text { sobre o novovacervolproduto que será oferecido } \\
\text { pela escola. Controlar o uso dos recursos e da sala } \\
\text { multimídias através de planilhas. }\end{array}$ \\
\hline Marialice & $\begin{array}{l}\text { Professora } \\
\text { coordenado } \\
\text { ra do } \\
\text { Ensino } \\
\text { Médio }\end{array}$ & $\begin{array}{l}\text { Matemática. } 22 \text { anos de magistério, sendo } \\
05 \text { nesta escola. Em virtude de sua } \\
\text { experiência profissional, acumulada no } \\
\text { magistério e como professora } \\
\text { coordenadora da oficina pedagógica da } \\
\text { Diretoria de ensino, vem possibilitando aos } \\
\text { docentes formação em serviço conectada } \\
\text { ao currículo da SEE. Apresentando assim } \\
\text { idéias inovadoras nos processos de } \\
\text { elaboração de situações didáticas. }\end{array}$ & $\begin{array}{l}\text { Preparar as pautas e registros das atas das reuniões } \\
\text { para: planejamento do plano de empreendimento, } \\
\text { capacitação em serviço dos docentes sobre o uso dos } \\
\text { recursos multimídias e reflexões coletivas sobre o } \\
\text { processo do projeto. Elaborar planilhas de observação } \\
\text { para acompanhamento e controle da execução e da } \\
\text { avaliação das ações do projeto. Observar in locus as } \\
\text { ações, tendo como base indicadores. Elaborar planilha de } \\
\text { registro do feedback e encaminhamentos acordados. } \\
\text { Realizar feedback individual e coletivo com todos que } \\
\text { realizarão as ações para aprimoramento. Estimular a } \\
\text { troca de experiências entre os docentes. }\end{array}$ \\
\hline
\end{tabular}

\section{Principais processos}

Para a execução do empreendimento, a tabela abaixo deixa claro o perfil da equipe e os principais processos de trabalho, sendo:

\begin{tabular}{|c|c|c|}
\hline Processos do empreendimento & colaborador & Perfil necessário \\
\hline $\begin{array}{l}\text { Participar do planejamento do projeto, } \\
\text { executar situações didáticas (ações) com } \\
\text { as turmas; receber alunos para pesquisa } \\
\text { no contraturno; e responsabilizar-se pelo } \\
\text { ambiente multimídia; }\end{array}$ & $\begin{array}{c}\text { Lucinete } \\
\text { (professora } \\
\text { responsável pela } \\
\text { sala de leitura) }\end{array}$ & $\begin{array}{l}\text { Conhecimento: professora designada para atuar na sala de } \\
\text { leitura, com experiência acumulada na escola há mais de } 8 \\
\text { anos, participa de formações continuadas e produz projetos } \\
\text { inovadores. } \\
\text { Habilidade: desenvolve projetos inovadores e } \\
\text { interdisciplinares, excelente comunicação verbal e expressiva } \\
\text { e bom relacionamento com os alunos. } \\
\text { Atitude: domínio da gestão de sala de aula, domínio de } \\
\text { estratégias de leitura e escrita, criatividade, responsabilidade e } \\
\text { comprometimento profissional. }\end{array}$ \\
\hline $\begin{array}{l}\text { Participar: da pesquisa de interesses dos } \\
\text { alunos, do planejamento do projeto } \\
\text { Profissões, da execução das situações } \\
\text { didáticas (ações em ambientes } \\
\text { multimídias, palestras, visitações...) e da } \\
\text { avaliação do projeto }\end{array}$ & $\begin{array}{c}\text { Equipe de } \\
\text { professores da UE }\end{array}$ & $\begin{array}{l}\text { Conhecimento: } 80 \% \text { dos professores são concursados e } 20 \% \\
\text { contratados, experientes, participam de formações } \\
\text { continuadas e produzem projetos inovadores. } \\
\text { Habilidade: gostam de inovação tecnológica e de oportunizar } \\
\text { um ensino fundamentado nas modalidades organizativas do } \\
\text { tempo e espaço didático. } \\
\text { Atitude: domínio da gestão de sala de aula, criatividade, } \\
\text { responsabiliade com a aprendizagem e cumprimento das } \\
\text { metas. }\end{array}$ \\
\hline
\end{tabular}




\section{Elza Aparecida da Cruz}

\begin{tabular}{|c|c|c|}
\hline $\begin{array}{l}\text { Confeccionar materiais para as reuniões } \\
\text { de divulgação do projeto, digitar os } \\
\text { horários, e afixar nos murais. }\end{array}$ & $\begin{array}{l}\text { Maurício (agente de } \\
\text { organização) }\end{array}$ & $\begin{array}{l}\text { Conhecimento: concursado; curso superior em } \\
\text { Comunicações e PGE. } \\
\text { Habilidade: domina os processos necessários a sua função. } \\
\text { Atitude: proativo, autonomia, agilidade, organização e } \\
\text { responsabilidade. }\end{array}$ \\
\hline $\begin{array}{l}\text { Garantir a limpeza das salas e } \\
\text { manutenção dos equipamentos. }\end{array}$ & Neinha e Ilda & $\begin{array}{l}\text { Conhecimento: serviço terceirizado, capacitadas pela } \\
\text { empresa. } \\
\text { Habilidade: ser cuidadosa ao manusear os equipamentos que } \\
\text { compõem o ambiente multimídia. Serão capacitadas para } \\
\text { limpá-los corretamente. } \\
\text { Atitude: zelo em manter os ambientes organizados para o } \\
\text { bem-estar dos alunos. }\end{array}$ \\
\hline \multicolumn{3}{|l|}{ Legenda } \\
\hline \multicolumn{3}{|l|}{ Processo Pedagógico } \\
\hline \multicolumn{3}{|l|}{ Processo Administrativo } \\
\hline \multicolumn{3}{|l|}{ Processo de Apoio } \\
\hline
\end{tabular}

\section{Plano financeiro}

Investimentos (despesas de capital)

\begin{tabular}{|c|c|c|c|}
\hline \multicolumn{1}{|c|}{ Item } & Ano1 & Ano2 & Ano3 \\
\hline Obras e infraestrutura & $4.250,00$ & 0,00 & 0,00 \\
\hline Obras pintura e instalações & $4.250,00$ & & \\
\hline Material permanente & & & 0,00 \\
\hline 05 datashows SONY & $14.096,05$ & & \\
\hline 01 home theater SONY & $12.408,05$ & & \\
\hline 10 livros & $1.398,00$ & & \\
\hline Total & 290,00 & & \\
\hline
\end{tabular}

\section{Detalhamento:}

05 datashows: projetor Sony - VPL - DX 140, 3200 Lumens;

Home Theater: Sony com blu-ray, 3D e DVD Player - 850W, 5.1 canais;

Livro: "Jovens Falcões" de Eduardo Lyra;

Obras e instalações: pintura em cinco salas de aula e na Sala de Leitura, mais as cinco instalações dos datashows nas salas pintadas.

\section{Despesas correntes}


PROFISSÕES: Tantas e quais escolher?

\begin{tabular}{|cc|c|c|c|}
\hline \multicolumn{1}{|c|}{ Material de Consumo } & Total ANO 1 & Total ANO 2 & Total ANO 3 \\
\hline papel sulfite A4 & & $3.360,00$ & $3.460,80$ & $3.564,62$ \\
\hline & Total & $3.360,00$ & $3.460,80$ & $3.564,62$ \\
\hline Passagens e Locomoção & & Total ANO 1 & Total ANO 2 & Total ANO 3 \\
\hline & Total & 0 & 0 & 0 \\
\hline Serviços de Terceiros & & Total ANO 1 & Total ANO 2 & Total ANO 3 \\
\hline fretamento de ônibus & $3.000,00$ & $3.000,00$ & $3.000,00$ \\
\hline manutenção dos equipamentos & & 600,00 & 600,00 & 600,00 \\
\hline & Total & $3.600,00$ & $3.600,00$ & $3.600,00$ \\
\hline \multicolumn{2}{|c|}{ Total das Despesas Correntes } & $6.960,00$ & $7.060,80$ & $7.164,62$ \\
\hline
\end{tabular}

Detalhamento:

Papel Sulfite: 02 caixas com 20 resmas por mês, uma resma por turma;

Fretamento de ônibus: excursões mensais por turma para levá-los às Universidades e Faculdades locais, como também, à Feira das Profissões.

Obs: muitos dos materiais didáticos (filmes, reportagens notícias mapas, revistas eletrônicas, músicas...) serão baixados pela Internet sem custo.

Despesas administrativas e de pessoal

Valor utilizado como contrapartida

\begin{tabular}{|c|c|c|c|}
\hline \multicolumn{5}{|c|}{ Projeção das Despesas Administrativas e de Pessoal } \\
\hline Adminstrativas & Total ANO 1 & Total ANO 2 & Total ANO 3 \\
\hline Energia elétrica & $3.600,00$ & $3.708,00$ & $3.819,24$ \\
\hline Marketing & 480,00 & 489,60 & 499,39 \\
\hline Pessoal & $4.080,00$ & $4.197,60$ & $4.318,63$ \\
\hline Diretora & Total ANO 1 & Total ANO 2 & Total ANO 3 \\
\hline Coordenadora Pedagógica & 420,00 & 420,00 & 420,00 \\
\hline Professora da Sala de Leitura & 960,00 & 960,00 & 960,00 \\
\hline Gerente Administrativo & $6.000,00$ & $6.000,00$ & $6.000,00$ \\
\hline & 480,00 & 480,00 & 480,00 \\
\hline Total das Despesas Correntes & $7.860,00$ & $7.860,00$ & $7.860,00$ \\
\hline
\end{tabular}


Necessidade de recursos

\begin{tabular}{|c|c|c|c|c|}
\hline \multicolumn{5}{|c|}{ Cálculo da Necessidade de Recursos } \\
\hline Item & ANO 1 & ANO 2 & ANO 3 & TOTAL \\
\hline I. Total das Despesas Correntes & $6.960,00$ & $7.060,80$ & $7.164,62$ & $21.185,42$ \\
\hline Material de Consumo & $3.360,00$ & $3.460,80$ & $3.564,62$ & $10.385,42$ \\
\hline Passagens e Despesas com Locomoção & 0,00 & 0,00 & 0,00 & 0,00 \\
\hline Serviços de Terceiros & $3.600,00$ & $3.600,00$ & $3.600,00$ & $10.800,00$ \\
\hline II. Total de Despesas Administrativas & $12.000,00$ & $12.348,00$ & $12.706,20$ & $37.054,20$ \\
\hline III. Total de Despesas com Pessoal & $14.160,00$ & $14.160,00$ & $14.160,00$ & $42.480,00$ \\
\hline IV. Total de Despesas de Capital (investimentos) & $18.346,05$ & 0,00 & 0,00 & $18.346,05$ \\
\hline Necessidade de Recursos (I+||+|||+|V) & $51.466,05$ & $33.568,80$ & $34.030,82$ & $119.065,67$ \\
\hline Recursos Edital & $25.306,05$ & $7.060,80$ & $7.164,62$ & $39.531,47$ \\
\hline Recursos da Organização (contrapartida) & $26.160,00$ & $26.508,00$ & $26.866,20$ & $79.534,20$ \\
\hline
\end{tabular}

Validações:

\begin{tabular}{|l|c|c|c|}
\hline \multicolumn{1}{|c|}{ Itens Financiáveis } & Valores \\
Consolidades & $\%$ & Validação \\
\hline Despesas Correntes & $\mathbf{2 1 . 1 8 5 , 4 2}$ & $54 \%$ & \\
\hline Despesas de Capital (máximo de $50 \%$ do projeto) & $18.346,05$ & $46 \%$ & $0 k:-50 \%$ \\
\hline Total de Recursos Solicitados & $39.531,47$ & $100 \%$ & Ok: $<100$ mil \\
\hline
\end{tabular}

\begin{tabular}{|c|c|}
\hline \multicolumn{2}{|c|}{ Contrapartida } \\
\hline Valor total da contrapartida & $\mathbf{7 9 . 5 3 4 , 2 0}$ \\
\hline Valor solicitado ao edital pelo projeto & $39.531,47$ \\
\hline Percentual:contrapartida / recursos solicitados & $201 \%$ \\
\hline
\end{tabular}

